\title{
Stock Market Return and Household Financial Investments
}

\author{
Haiyang Jiang \\ Olin Business School, Washington University in St. Louis, St. Louis, MO 63130, US \\ j53418378@163.com
}

\begin{abstract}
The purpose of this study project was to explore the link between household investment and stock market fluctuations in the United States. The research's aims are to identify the relationship between household investment and the stock market index in the United States, as well as to establish the direction of the relationship between household investment and the stock market index in the United States. Multiple linear regression analysis was performed to capture the influence and direction of the connection. The findings revealed that while household income has a positive but modest influence on stock market performance, and there is positive statistically significant impact on the household investment, according to the study. The evidence for the finding revealed a bidirectional link between the investment by the households and the stock market index.
\end{abstract}

\section{CCS CONCEPTS}

- Social and professional topics; • Applied computing; • Law, social and behavioral sciences; $\bullet$ Economics;

\section{KEYWORDS}

stock market performance, stock index, household financial investments

\section{ACM Reference Format:}

Haiyang Jiang. 2021. Stock Market Return and Household Financial Investments. In 2021 th International Conference on E-Business and Internet (ICEBI 2021), October 15-17, 2021, Singapore, Singapore. ACM, New York, NY, USA, 4 pages. https://doi.org/10.1145/3497701.3497719

\section{INTRODUCTION}

The stock market performance has significant impacts in a variety of areas. Stock markets have been increasingly popular as a topic of conversation in the general public's everyday life, and elements that impact stock market performance have become a central topic of discussion in the area of finance as the economy has developed. Individuals frequently use the terms "overall economic conditions," "industry conditions," and "political conditions" when discussing factors that influence the stock market return. However, there has been little investigation on the impact at the household level.

The purpose of this paper is to identify the link between household financial investment and the return on the stock market. When

Permission to make digital or hard copies of all or part of this work for personal or classroom use is granted without fee provided that copies are not made or distributed for profit or commercial advantage and that copies bear this notice and the full citation on the first page. Copyrights for components of this work owned by others than ACM must be honored. Abstracting with credit is permitted. To copy otherwise, or republish, to post on servers or to redistribute to lists, requires prior specific permission and/or a fee. Request permissions from permissions@acm.org.

ICEBI 2021, October 15-17, 2021, Singapore, Singapore

(c) 2021 Association for Computing Machinery.

ACM ISBN 978-1-4503-8565-7/21/10 . \$15.00

https://doi.org/10.1145/3497701.3497719 it comes to an economy, investment is an important component of success. Gross domestic product (GDP) has a substantial link with the stock market [1]. So, we might say that investment has an influence on the stock market, and that household investment behavior, which is a component of investment, may likewise have influence on the stock market. Furthermore, because growing stock market returns are driven by increasing stock market investment, we may also hypothesize that there is a link between financial investment and stock market return. As households account for a large portion of the broader economy, their financial strategy may be influential to the stock market index as well.

The research was carried out using two separate multiple linear regression models to examine the relationship between different household financial investments and the return on the stock market. The quarterly household investment in the United States is used to calculate the household financial investment, and the quarterly S\&P500 index is used to calculate the stock market return. Because the stock market's performance is impacted by the state of the economy, we include the 10-year treasury bill yield and the inflation rate in the United States as extra control variables.

\section{MAIN RESEARCH QUESTION}

According to the proposed study, the relationship between household financial investment on the stock market return in the United States will be investigated. In particular, the research will examine the correlation between the household investment and the performance of the stock market in the United States, the direction of the correlations between the two variables, and how large the two variables have influence on each other. The research is being conducted because we have discovered a vacuum in the literature that is examining financial decisions and stock market returns at the household level. The ultimate goal of this article is to conduct a critical evaluation of the probable determinants of stock market performance.

\section{LITERATURE REVIEW}

We were unable to locate any previous research that focused specifically on the link between household financial investment and the stock market index, discovering by the data from past years. The reason for this may be because individuals have a tendency to assume that household financial strategy accounts for a minor portion of total investment, not just in the stock market, but also in the whole economy. However, it has been demonstrated that decisions made by households have a substantial impact on the economy.

There has only been a little amount of study into the relationship between foreign investment and stock market performance. Anayochukwu [2] demonstrated the a positive relationship and unidirectional causality between foreign portfolio investment and stock market performance, utilizing evidence from Nigeria. Ngobe and Kalu [3] also discovered that foreign direct investment had a 
substantial influence for the stock market growth. As evidenced by the negative relationship between foreign direct investment and private investment [4] and the fact that the household investment sector is a subset of the private investment sector [5], we may be able to establish relationship between the household investment sector and the foreign investment sector, thus, there may also be a direct connection between the household investment and the stock market return.

On the other hand, people appear to limit the amount of money they invest into the stock market during a period of "bear market" circumstances, according to the data presented in this study. A further drop in the return on the stock market would occur from investors withdrawing their assets in a herding behavior, particularly during periods of declining markets [6] An investigation on the influence of the stock market on household investment discovered that the COVID-19 produces a 9.5 percent drop in the overall amount of household investment, as an illustration of this effect [7]. In addition, Anthony-Orji et al. [8] also proved the effect of the stock market development with the private investment, while household investment is part of the private investment. Based on those research, we could determine the influence of the stock market on household investment through our research. However, previous research, on the other hand, have only taken into consideration the influence during a period of declining market performance and have ignored the effects during a period of strong market performance.

Overall, prior academics in the field of finance have forgotten to do formal study on the relationship between household financial decision-making and stock market performance in order to better understand this relationship. In accordance with the findings of the previous research, the purpose of this study is to formally address the link between household investment and performance of the stock market, as well as the direction of correlation. It is anticipated that this study will make significant contributions to the estimation of future stock market returns and household investment amounts.

\section{METHODOLOGY}

\subsection{Data}

Multiple linear regression is used in this research to investigate the link between household financial decision making and stock market return among the underlying data of the United States household investment, the S\&P500 stock market index, with some macroeconomic variables such as the inflation rate, inflation. In addition, the direction of causation between household financial strategy and stock market success is determined in this paper.

The data used in this research was collected quarterly from 1962Q1 to 2021Q1. BEA gave sufficient data on household financial investments, while MacroTrend provides data on S\&P500 index. The interest rate, U.S. 10-year treasury bill, was obtained from the FRED, and the data on the inflation rate was obtained from the U. S. Inflation Calculator. Prices and the index are in US dollars in the absolute value. Interest rate and inflation are in percentage.

\subsection{Model}

A multiple linear regression model is used to determine the correlation between the S\&P500 stock market index and financial investments made by individuals and families. It will be necessary to employ two regression models to investigate the direction of the causation between the two variables.

$$
\begin{aligned}
& S M I=\alpha_{0}+\beta_{1} H I N V+\beta_{2} I N R+\beta_{3} I N F+\varepsilon \\
& H I N V=\alpha_{0}+\beta_{1} S M I+\beta_{2} I N R+\beta_{3} I N F+\varepsilon
\end{aligned}
$$

Where

$\alpha 0=$ constant or intercept

$\mathrm{SMI}=\mathrm{S} \& \mathrm{P} 500$ index

HINV = household investment amount

INR = U.S. 10-year treasury bills (as percentage)

$\mathrm{INF}=$ U.S. inflation rate (as percentage)

\subsection{Descriptive Statistics}

Figure 1 depicts the behavior of SMI, HINV, INR, and INF during the course of the research. During the test of data behavior, every variable had some sort of trend, which suggested that the data had a nonstationary feature.

The descriptive statistics for each of the four variables are shown in the Table 1 . The standard deviations of the 10-year treasury bill and the inflation rate in the United States are both very small, but the standard deviations of household investment and the stock market index are both substantially larger. All four variables have a positive skewness to them.

Table 2 displayed the correlation matrix including four different factors. Based on the information, we were able to conclude that the S\&P500 stock market index had a statistically strong correlation with the amount of money that households invested. Both U.S. 10year treasury bill and inflation rate are negatively correlated with the S\&P500 stock market index and the household investment. The 10-year treasury bill and the inflation rate in the United States were shown to have a positive correlation with one another.

\subsection{Results}

The results of the multiple linear regression model (2) were shown in Table 3. Based on the findings, we may conclude that household investment has a positive but only a minor influence on the stock market index. The interest rate has a statistically significant negative correlation with the stock market index, but the inflation rate has a statistically significant positive correlation with the stock market index.

The results of the multiple linear regression model (2) were shown in Table 4. The findings revealed that the stock market index had a statistically meaningful beneficial influence on household investment. A unit of increase of the stock market leads to 324.48 dollar increase in the household investment. A substantial amount of impact is also exerted by interest rates and inflation rates on the household investment. The interest rate had a positive connection with household investment, but the inflation rate had a negative link with household investment.

\section{DISCUSSION}

In this study, the objective is to explore the link between household investments and the stock market index, along with the direction of that relationship. In this study, it was proven that the positive bidirectional correlation between household investments and the stock market index holds. 

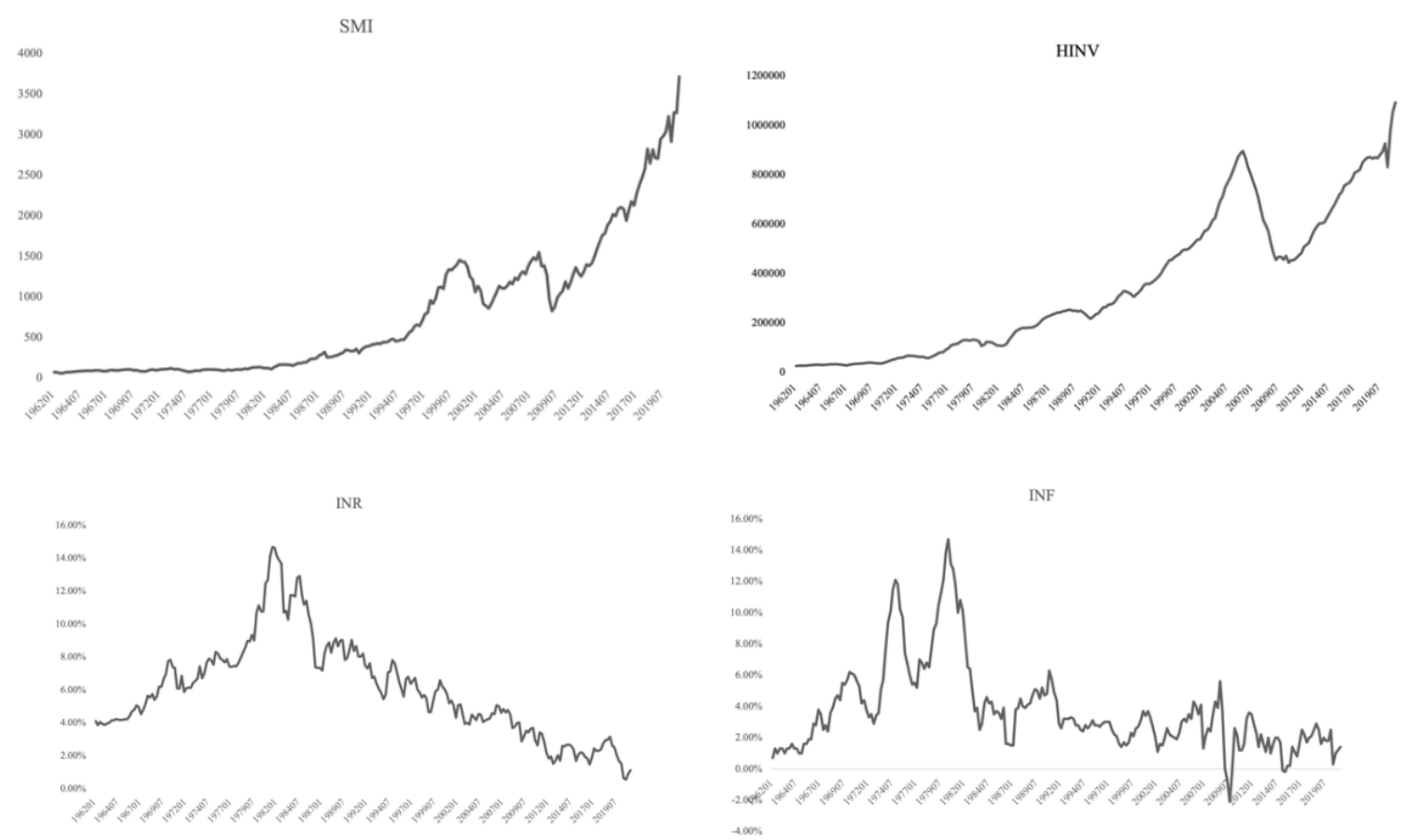

Figure 1: Multiple Line Graphs

Table 1: Descriptive Statistics

\begin{tabular}{lllll}
\hline & SMI & HINV & INR & INF \\
\hline Number & 237 & 237 & 237 & 237 \\
Mean & 771.0578 & 346660.1 & 6.021435 & 3.751477 \\
Std. Dev & 827.7663 & 284144.9 & 2.968022 & 2.850046 \\
Min & 56.62 & 26409 & 0.55 & -2.1 \\
P1 & 65.24 & 26892 & 0.88 & -0.2 \\
P50 & 387.81 & 251492 & 5.77 & 3 \\
P99 & 3269.96 & 976708 & 14.14 & 13.1 \\
Max & 3714.24 & 1091801 & 14.67 & 14.7 \\
Skewness & 1.294163 & 0.618345 & 0.643609 & 1.565219 \\
Kurtosis & 4.051030 & 2.168605 & 3.215254 & 5.552518 \\
\hline
\end{tabular}

Table 2: Correlation Matrix

\begin{tabular}{lllll}
\hline & SMI & HINV & INR & INF \\
\hline SMI & 1.0000 & & & \\
HINV & 0.9235 & 1.0000 & & \\
INR & -0.6833 & -0.6142 & 1.0000 & 1.0000 \\
INF & -0.4609 & -0.4522 & 0.6753 & \\
\hline
\end{tabular}

Table 3: Regression Results for Model (1)

\begin{tabular}{lllllll}
\hline SMI & Coefficient & Std. Err. & t-statistic & p-value & [95\% Conf. Interval] \\
\hline HINV & 0.0023669 & 0.0000852 & 27.77 & 0.000 & 0.002199 & 0.0025348 \\
INR & -62.1458 & 9.866311 & -6.30 & 0.000 & -81.58438 & 42.70722 \\
INF & 16.56211 & 9.090769 & 1.82 & 0.070 & -1.3485 & 34.47272 \\
\hline
\end{tabular}


Table 4: Regression Results for Model (2)

\begin{tabular}{|c|c|c|c|c|c|c|}
\hline HINV & Coefficient & Std. Err. & t-statistic & $\mathrm{p}$-value & \multicolumn{2}{|c|}{ [95\% Conf. Interval] } \\
\hline SMI & 324.4865 & 11.68309 & 27.77 & 0.000 & 301.4685 & 347.5045 \\
\hline INR & 7556.196 & 3920.808 & 1.93 & 0.055 & -168.5711 & 15280.96 \\
\hline INF & -6964.905 & 3359.017 & -2.07 & 0.039 & -13582.83 & -346.9779 \\
\hline
\end{tabular}

The degrees of the effects of the household investment and the stock market return on each other are extremely different. Household investment has just a little impact on the stock market performance, but the stock market index has a significant impact on the amount of money that households invest. In most cases, the findings are consistent with our predictions and hypotheses, which projected that the two variables would have a positive influence on each other. Although we anticipated a gap between the influence of the stock market index on household investment and the effectiveness of household investment and the stock market index, we were surprised by the magnitude of the discrepancy.

The fact that household investment has just a minor influence on the stock market index is in contradiction to the fact that foreign investment has a significant impact [4]. The findings also show that the stock market performance has a significant impact on household investment, with households investing more money during periods of rising stock markets and less money during periods of declining stock markets. This research produced results with corroborate the idea by [7] of the decreasing household investment during the COVID-19 Pandemic and could indirectly support the study that the stock market development increasing the private investment [8], as household investment is part of the private investment.

Furthermore, we discovered the relationship of interest rate and inflation rate with the stock market index and the household investment. The interest rate had a significant negative association with performance of the stock market and a large positive relationship with the investment made by households. While the connection of the interest rate and the stock market index are in line with the earlier research made by Nordin et al. [9], the positive correlation between the interest rate and the household investment is actually inconsistent with the previous findings that the increasing interest rate decrease the overall investment [10]. In addition, the inflation rate is positively correlated with the performance of stock market and a significant negative correlation with the amount of money that households invest.

Previous work has suggested the stock market index has impact on the household financial decision during the recession [7]. The current research has been established that no previous studies have analyzed the impact of household investment for the stock market performance and effect of the stock market performance on the household investment in the good stock market condition. This research contributes to this gap by providing giving empirical evidence of the link between the two variables, as well as evidence of the direction of the correlation.

The limitation of this research is that the data for doing this is relatively short, and we only evaluated the findings based on data from the United States of America. As a recommendation, future researchers should do an empirical study based on information from other nations and try to find more data to support their findings.

\section{CONCLUSION}

Specifically, the purpose of this study was to establish a link between household investment and the stock market index, as well as to assess the direction of the association. According to the findings of the study, household investment has only a modest positive influence on the stock market index, but the stock market index has a significant positive effect for the amount of money invested by households in the stock market. This work contributes to the filling of a research gap in the field of finance and improves our understanding of the two variables under investigation. The investigation was only done with data from the United States, which is a major limitation of this study. It would be interesting to see how the connection will work out in different nations. If additional data could be gathered, it would be extremely beneficial to do further study. Furthermore, we recommend that more positive information about the capital market be released during a period of declining stock market with the aim to increase household confidence in the stock market and, as a result, prevent the stock market from further declining caused by the decreasing investment of households.

\section{REFERENCES}

[1] Jareño, F., \& Negrut, L. (2015). US stock market and macroeconomic factors. Journal of Applied Business Research (JABR), 32(1), 325. doi:10.19030/jabr.v32i1.9541

[2] Anayochukwu, O. B. (2012). The impact of stock market returns on foreign portfolio investment in Nigeria. IOSR Journal of Business and Management, 2(4), 10-19. doi: $10.9790 / 487 \mathrm{x}-0241019$

[3] Ngobe, D., \& Kalu, E. (2020). Relationship between foreign direct investment and stock market development in a small Southern Africa economy. Jurnal Akuntansi dan Keuangan Indonesia, 17(2). doi:10.21002/jaki.2020.10

[4] Morrissey, O., \& Udomkerdmongkol, M. (2012). Governance, private investment and foreign direct investment in developing countries. World Development, 40(3), 437-445. doi:10.1016/j.worlddev.2011.07.004

[5] Fitzgerald, E. V. (1992). Private sector investment and savings behaviour: The policy implications of capital account disaggregation (The Distinguishedl lecture). The Pakistan Development Review, 31(4I), 491-510. doi:10.30541/v31i4ipp.491-510

[6] Yao, J., Ma, C., \& He, W. P. (2014). Investor herding behaviour of Chinese stock market. International Review of Economics \& Finance, 29, 12-29. doi:10.1016/j.iref.2013.03.002

[7] Yue, P., Gizem Korkmaz, A., \& Zhou, H. (2020). Household financial decision making amidst the COVID-19 pandemic. Emerging Markets Finance and Trade, 56(10), 2363-2377. doi:10.1080/1540496x.2020.1784717

[8] Anthony-Orji, O. I., Orji, A., \& Ogbuabor, J. E. (2018). Analysis of stock market development, foreign private investment and economic growth in Nigeria. Journal of Infrastructure Development, 10(1-2), 1-17. doi:10.1177/0974930618773254

[9] Nordin, N., Nordin, S., \& Ismail, R. (2020). The impact of commodity prices, interest rate and exchange rate on stock market performance: An empirical analysis from Malaysia. Malaysian Management Journal. doi:10.32890/mmj.18.2014.9015

[10] Malawi, A., \& Bader, M. (2010). The impact of interest rate on investment in Jordan: A Cointegration analysis. Journal of King Abdulaziz University-Economics and Administration, 24(1), 199-209. doi:10.4197/eco.24-1.6 